\title{
Application of Raman spectroscopy method to the diagnostics of caries development
}

\author{
Elena V. Timchenko ${ }^{1}$, Pavel E. Timchenko ${ }^{1 *}$, Larisa T. Volova², Anastasiya Yu. Rosenbaum ${ }^{2}$, Arina \\ Yu. Kulabukhova ${ }^{1}$, Larisa A. Zherdeva ${ }^{1}$, Irina F. Nefedova ${ }^{2}$ \\ ${ }^{1}$ Laser and biotechnical systems department, Samara State Aerospace University, Russia \\ ${ }^{2}$ Institute of Experimental Medicine and Biotechnologies, Samara State Medical University, Russia \\ *e-mail: timpavel@mail.ru
}

\begin{abstract}
The object of study were human teeth with caries cavities and healthy teeth extracted for orthopaedic indications. The main method of study was Raman spectroscopy. We revealed the specific features of Raman spectra for the healthy tooth tissues impaired ones and the tissues affected by caries. The optical criteria are established that allow cares detection and assessment, as well as the detection of precaries impairment of the tooth tissues. The results were analysed in comparison with the data of the chemical analysis performed using a raster electron microscope. (C) 2015 Samara State Aerospace University (SSAU).
\end{abstract}

Keywords: spectroscopy, Raman scattering, tooth, caries.

Paper \#2680 received 2015.10.14; revised manuscript received 2015.12.20; accepted for publication 2015.12.21; published online 2015.12.27.

\section{References}

1. B. A. Dye, S. Tan, V. Smith, B. G. Lewis, L. K. Barker, G. Thornton-Evans, P. I. Eke, E. D. Beltrán-Aguilar, A. M. Horowitz, and C. H. Li, "Trends in oral health status: United States, 1988-1994 and 1999-2004," Vital Health Stat 11(248), 1-92 (2007).

2. R. Ramakrishnaiah, G. ur Rehman, S. Basavarajappa, A. A. Al Khuraif, B. H. Durgesh. A. S. Khan, and I. ur Rehman, "Applications of Raman Spectroscopy in Dentistry: Analysis of Tooth Structure," Applied Spectroscopy Reviews 50(4), 332-350 (2015).

3. M. Miyazaki, H. Onose, and B. Moore, "Analysis of the dentin-resin interface by use of laser Raman spectroscopy," Dent. Mater 18(8), 576-580 (2002).

4. S. Yang, B. Li, A. Akkus, O. Akkus, and L. Lang, "Wide-Field Raman Imaging of Dental Lesions," Analyst 139(12), 3107-14 (2011).

5. A. C.-T. Ko, M. Hewko, M. G. Sowa, C. C. S. Dong, B. Cleghorn, and L.-P. Choo-Smith, "Early dental caries detection using a fibre-optic coupled polarization-resolved Raman spectroscopic system," Opt Express 16(9), 6274-6284 (2008).

6. I. Ionita, "Diagnosis of tooth decay using polarized micro-Raman confocal spectroscopy," Rom. Rep. Phys. 61, 567-574 (2009).

7. V. Bulatov, L. Feller, Y. Yasman, and I. Schechter, "Dental enamel caries (early) diagnosis and mapping by laser Raman spectral imaging,” Instrum. Sci. Technol. 36, 235-244 (2008).

8. Y. V. Mandra, A. S. Ivanov, S. L. Votyakov, D. V. Kiseleva, "Possible applications of Raman microspectroscopy to study structural features of the hard tissues of human teeth," Experimental and Clinical Dentistry 1, 24-28 (2011).

9. The Wetpaint Cariology Project.

10. SIRONE. The Dental Company.

11. E. V. Timchenko, P. E. Timchenko, L. T. Volova, Y. V. Ponomareva, and L. A. Taskina, "Raman spectroscopy of the organic and mineral structure of bone grafts," Quantum Electron 44(7), 696-699 (2014).

12. A. A. Dolzhikov, Histology of Tooth Tissue. A Manual for Independent Work of Dental Department Students, Belgorod State University, Belgorod (2007) [in Russian].

13. R. Kumar, G. P. Singh, K. M. Grønhaug, N. K. Afseth, C. de Lange Davies. J. O. Drogset, and M. B. Lilledahl, "Single Cell Confocal Raman Spectroscopy of Human Osteoarthritic Chondrocytes: A Preliminary Study," Int. J. Mol. Sci. 16(5), 9341-9353 (2015). 
14. I. Rehman, Z. Movasaghi, and S. Rehman, Vibrational Spectroscopy for Tissue Analysis, Series in Medical Physics and Biomedical Engineering, CRC Press, 271 (2012).

15. G. Mandair, and M. Morris, "Contributions of Raman spectroscopy to the understanding of bone strength," BoneKEy Reports 4, 620 (2015).

16. A. Downes, R. Mouras, and A. Elfick, “Optical Spectroscopy for Noninvasive Monitoring of Stem Cell Differentiation," Journal of Biomedicine and Biotechnology 2010, 101864 (2010).

17. C. Xu, and Y. Wang, "Chemical composition and structure of peritubular and intertubular human dentin revisited," Arch Oral Biol 57(4), 383-91 (2012).

18. C. C. Silva, H. H. B. Rocha, F. N. A. Freire, M. R. P. Santos, K. D. A. Saboia, J. C. Goes, and A. S. B. Sombra, "Hydroxyapatite screen-printed thick films: optical and electrical properties," Materials Chemistry and Physics 92(1), 260-268 (2005).

\section{Introduction}

Like in any other branch of medicine in stomatology the successful and efficient treatment begins from highquality teeth diagnostics. It is well known that caries is the most widespread and unpredictable problem in stomatology $[1,2]$. At the first stages it is symptomless, but later the progressing caries can lead to the development of pulpit and finally to the tooth extraction and the consequent patient's aesthetic problem. For the efficient and timely diagnosis the complete dental examination must include the investigation of hard tissues, caries leads to unnecessarily damage the organic matrix of tooth tissue, which subsequently loses its function of fixing mineral substrate, which leads to the formation caries defect, using a contactless and noninvasive diagnostic method.

Raman spectroscopy is one of possible methods of early diagnostics of the tooth hard tissue diseases. The advantage of the Raman spectroscopy is that this method is non-invasive, non-destructive and requires no sample preparation [3].

In [4] examined changes in the enamel mineral substrate using the method of Raman spectroscopy, cutting is perpendicular to the cross section of the tooth. The authors of [4] compared the enamel caries regions with the healthy regions of the tooth at 960 and $880 \mathrm{~cm}^{-}$ ${ }^{1}$ corresponding to $\left(\mathrm{PO}_{4}\right)^{3-}$ and $\left(\mathrm{CO}_{3}\right)^{2-}$ respectively, since at these peaks the difference between the healthy an caries tooth regions is clearly seen. It was also shown experimentally that the enamel contains high concentration of mineral components.

In refs [5] the authors assess the ratio of crosspolarised (the polarisation of scattered light is perpendicular to that of the incident light) and copolarised Raman spectra at $959 \mathrm{~cm}^{-1}$. It was found that the ratio of co- and cross-polarised Raman scattering intensities can be used to assess the degree of demineralisation.

In $[6,7,8]$, using the method of Raman spectroscopy determined that the difference between healthy and carious areas of enamel is well observed at wave number $959 \mathrm{~cm}^{-1}$, as well as the study of various intensities $\mathrm{PO}_{4}{ }^{3-}$ oscillations $\left(1043,590\right.$, and $\left.431 \mathrm{~cm}^{-1}\right)$ revealed a consistent change in the intensity of the spectra of carious areas compared to healthy. The spectral changes associated with demineralization by altering the elemental composition of the enamel. In stomatology there are a few instruments based on optical methods. One of them is the fluorescence-based device KaVo DIAGNOdent that can detect caries at early stages. However an essential drawback of this instrument is the false response, e.g. to the tooth plaque [9].

The tomography system ORTHOPHOS XG 3D possesses high resolution $(160 / 100 \mu \mathrm{m})$, allows precise diagnostics of caries complications, and determination of efficient technique and tactics of channel treatment. However, the examination using this instrument is accompanied with the exposure to radiation of both the patient and the doctor [10].

On the basis of Raman spectroscopy instruments used in dentistry, it has not been developed. Therefore, one of the most urgent tasks is to develop a rapid instrument on the basis of Raman spectroscopy.

The aim of this work was to apply the Raman spectroscopy method to the diagnostics of caries and tooth tissue degradation at its early stage.

\section{Materials and Methods of Study}

As objects we used 11 samples of molar and premolar teeth of patients with the caries diagnosis (K02). The Raman spectroscopy method was implemented using the experimental stand described earlier [11], which includes a high-resolution digital spectrometer Shamrock with integrated refrigerated storage, fiber optic probe for Raman spectroscopy (RS), combined with the laser module LuxxMasterLML-785.0RB -04. Processing of the spectra made in the program Wolfram Mathematica 8.

The measurements were performed along the lines shown in Fig. 1. The power was being $300 \mathrm{~mW}$ in the healthy region and $100 \mathrm{~mW}$ in caries one the exposure time being 20 seconds and a wavelength of $785 \mathrm{~nm}$.

In the course of the studies, we first carried out a series of test experiments to ensure that the action was non-invasive and to choose the optimal parameters of the setup varying the laser power from 50 to $300 \mathrm{~mW}$. The variation of the probe height above the object within the interval of $6-8 \mathrm{~mm}$ exerted inessential influence on the values of Raman lines intensity ratio (the error amounted to $3 \%$ ). 
The comparative analysis of the chemical composition was performed using the raster electron microscope (REM) JED - 2300 AnalysisStation (Japan).The objects of study were different tooth regions (enamel, dentin, cement) both in the normal condition and with caries lesion.

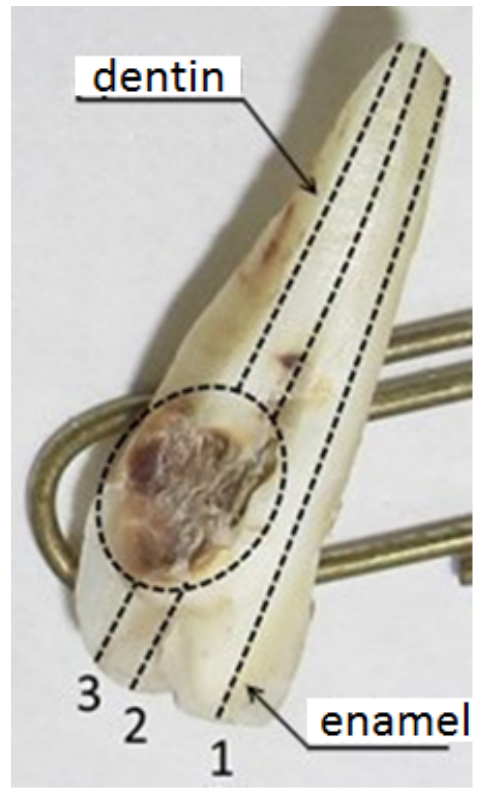

Fig. 1 The studied tooth: the tooth section shows the dentin and enamel regions and the lines passing them. The caries lesion of dentin and enamel in the crown part of the tooth is seen.

\section{Results}

Figure 2 presents the characteristic Raman spectra of the tooth tissues obtained as a result of the studies in the regions of lesion and healthy tooth.

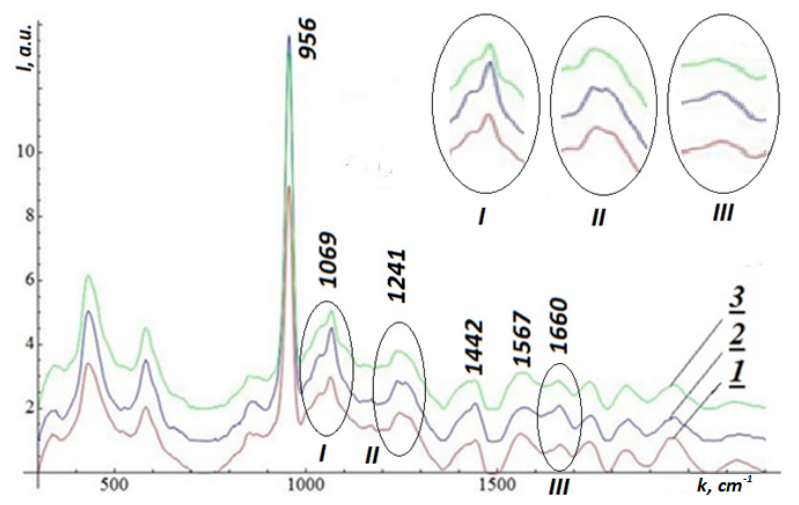

Fig. 2 Raman scattering spectra of healthy samples of the tooth cement (1), dentin (2), and enamel (3) tissues.

From Fig. 2 one can see the intensity decrease of the line at $1069 \mathrm{~cm}^{-1}$ corresponding to the vibration $v_{1}$ $\left(\mathrm{CO}_{3}\right)^{2-}$ due to the B-type substitutions where this group replaces $\mathrm{PO}_{4}{ }^{3-}$ and possesses less hardness. Besides that, the spectra differ in the intensities of lines at $1241 \mathrm{~cm}^{-1}$ and $1660 \mathrm{~cm}^{-1}$ corresponding to amide III and amide I respectively. The weakness of these lines is explained by the fact that the enamel is the hardest tissue in the human organism due to high content of inorganic substances (up to $97 \%$ ) namely the hydroxyapatite [12].

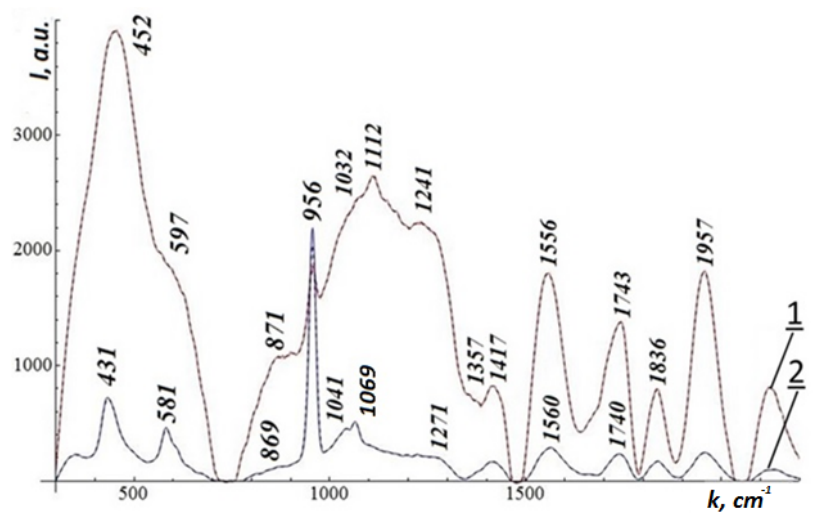

Fig. 3 Raman scattering spectra in the region of dentin with caries lesion (1) and healthy enamel (2) tooth tissues.

The analysis of Fig. 3 shows that for the samples of hard tissue affected by caries the main intensity changes are observed for the lines at 431, 581, 955, 1041, 1069 $\mathrm{cm}^{-1}$ corresponding to the phosphate and $1241 \mathrm{~cm}^{-1}$, corresponding to amide III; in the caries-affected tissues the line $1660 \mathrm{~cm}^{-1}$, corresponding to amide I manifests itself. For the samples with early stage of caries and weakened mineral component the spectra are transient. The early changes in the spectrum are mainly due to both the remineralisation of the tooth hard tissues and the change of the mineral component structure at the expense of replacement of more stable components with less stable ones.

The mineral component of the tooth is presented by various apatites possessing different properties:

$$
\begin{array}{ccc}
\mathrm{Ca}_{10}\left(\mathrm{PO}_{4}\right)_{6}(\mathrm{OH})_{2} \\
\downarrow & \uparrow & \uparrow \\
\mathrm{Z} & \mathrm{B} & \mathrm{A}
\end{array}
$$

Where the replacements of the following types are possible:

$\mathrm{Z}=\mathrm{Ca}^{2+} \cdot \mathrm{Na}^{+} \cdot \mathrm{Mg}^{2+}$;

$\mathrm{B}=\mathrm{PO}_{4}{ }^{3-} \cdot \mathrm{CO}_{3}{ }^{2-} \cdot \mathrm{HPO}_{4}{ }^{2-}$;

$\mathrm{A}=\mathrm{OH}^{-} \cdot \mathrm{CO}_{3}{ }^{2-} \cdot \mathrm{F}^{-} \cdot \mathrm{Cl}^{-}$.

The mineral component of the tooth is characterised by the vibration modes $v_{1}, v_{3}$. and $v_{4}\left(\mathrm{PO}_{3}\right)^{4-}$ in the hydroxyapatite molecule for which the Raman lines were recorded at 581, 647, 955, 1038 and $1169 \mathrm{~cm}^{-1}$ $[13,14]$ as well as by the lines of the vibration modes $v_{1}$ $\left(\mathrm{CO}_{3}\right)^{2-}$ of B-type substitutions, where $\left(\mathrm{PO}_{4}\right)^{3-}$ is replaced with $\left(\mathrm{CO}_{3}\right)^{2-}$ and A-type [14], where $\mathrm{OH}^{-}$is replace with $\left(\mathrm{CO}_{3}\right)^{2-}$ at $874,1067,1100$, and $1435 \mathrm{~cm}^{-1}$, respectively. Besides the Raman lines of proline and hydroxyproline the amide component is presented by the groups of amide III (in the region 1241-1271 $\mathrm{cm}^{-1}$ ) $[13,15]$, amide II (in the region 1520-1580 $\mathrm{cm}^{-1}$ ) [13], and amide $I$ (in the region $1630-1680 \mathrm{~cm}^{-1}$ ) $[13,15]$. The 
recorded Raman bands correspond to the vibrational modes presented in Table 1.

Table 1 Interpretation of Raman spectra.

\begin{tabular}{|c|c|}
\hline $\begin{array}{l}\text { Wavenumber, } \\
\mathrm{cm}^{-1}\end{array}$ & Fragment. vibration \\
\hline 431 & $\mathrm{v}_{2}$ symmetric bending mode of $\left(\mathrm{PO}_{4}\right)^{3-}[2]$ \\
\hline 581 & $\mathrm{v}_{4}$ asymmetric bending mode of $\left(\mathrm{PO}_{4}\right)^{3-}[2]$ \\
\hline 647 & $\mathrm{v}_{4}\left(\mathrm{PO}_{4}\right)^{3-}[2]$ \\
\hline 812 & $\mathrm{O}-\mathrm{P}-\mathrm{O}$ stretch[16] \\
\hline 850 & associated with proline[17] \\
\hline 874 & $\mathrm{v}_{2}\left(\mathrm{CO}_{3}\right)^{2-}[17]$ \\
\hline 955 & $\mathrm{v}_{1}$ symmetric stretching mode of $\left(\mathrm{PO}_{4}\right)^{3-}[2]$ \\
\hline 1004 & phenylalanine [13] \\
\hline 1038,1169 & $\begin{array}{l}\mathrm{v}_{3} \text { asymmetric stretching mode of }\left(\mathrm{PO}_{4}\right)^{3-} \\
{[2]}\end{array}$ \\
\hline 1069 & $\begin{array}{l}v_{1} \text { symmetric stretching mode of type } B \\
\left(\mathrm{CO}_{3}\right)^{2-}[2]\end{array}$ \\
\hline 1100 & $\begin{array}{l}v_{1} \text { symmetric stretching mode of type } A \\
\left(\mathrm{CO}_{3}\right)^{2-}[2]\end{array}$ \\
\hline 1241,1271 & Amide III (N-H) [2] \\
\hline 1435 & $\mathrm{CO}_{3}$ absorption of carbonate [17] \\
\hline 1567 & amide II [17] \\
\hline 1660 & Amide I $(C=0)[2]$ \\
\hline 1741 & $\mathrm{C}-\mathrm{O}-\mathrm{C}[17]$ \\
\hline
\end{tabular}

Since decay will damage the dental tissue organic matrix, which subsequently lose its fixing function mineral substrate, which leads to the formation of defect carious therefore been introduced for the diagnosis of the following factors:

$$
\begin{aligned}
& \mathrm{D}=\mathrm{I}_{956} / \mathrm{I}_{1069} \\
& \mathrm{~K}=\mathrm{I}_{1660} / \mathrm{I}_{1241},
\end{aligned}
$$

where $\mathrm{Ii}$ is the intensity of the line having the wavenumber $\mathrm{i}$; D is the proportionality factor of the variation of content of calcium carbonate ions in the tooth tissue (replacement of $\left(\mathrm{PO}_{4}\right)^{3-}$ ions with $\left(\mathrm{SO}_{3}\right)^{2-} \mathrm{B}$ type); $\mathrm{K}$ is the coefficient, characterizing the replacement of amide I with amide III.

The 2D dependences are plotted on Fig. 4.
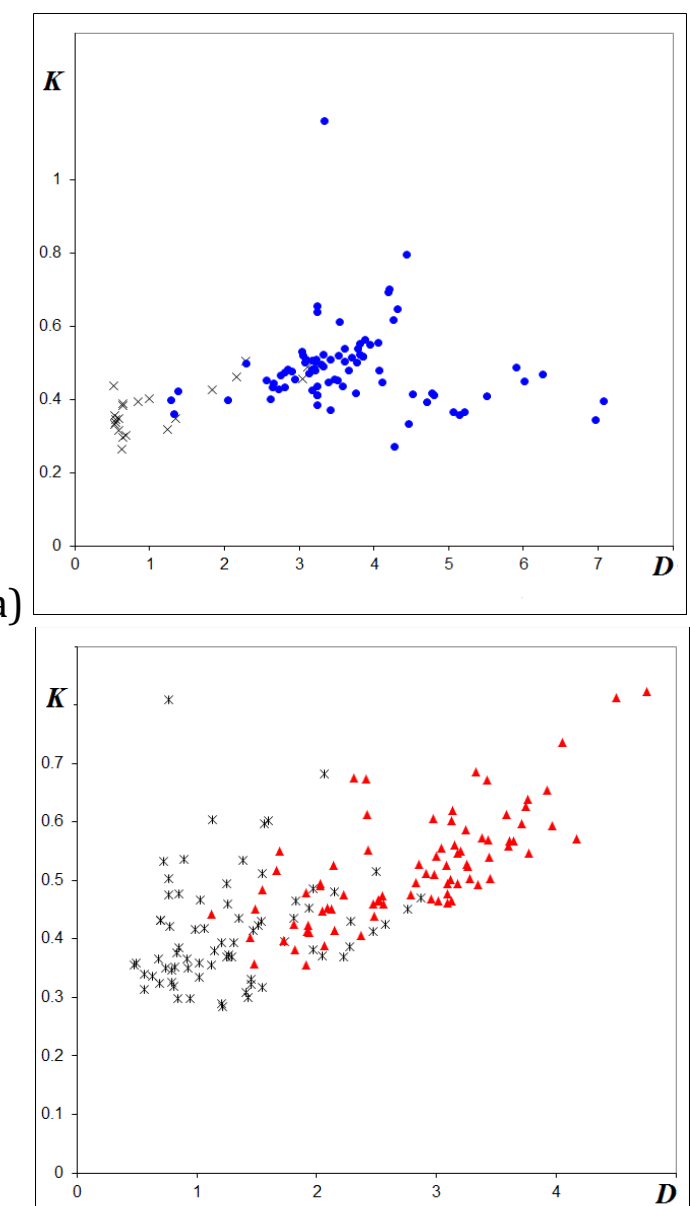

b)

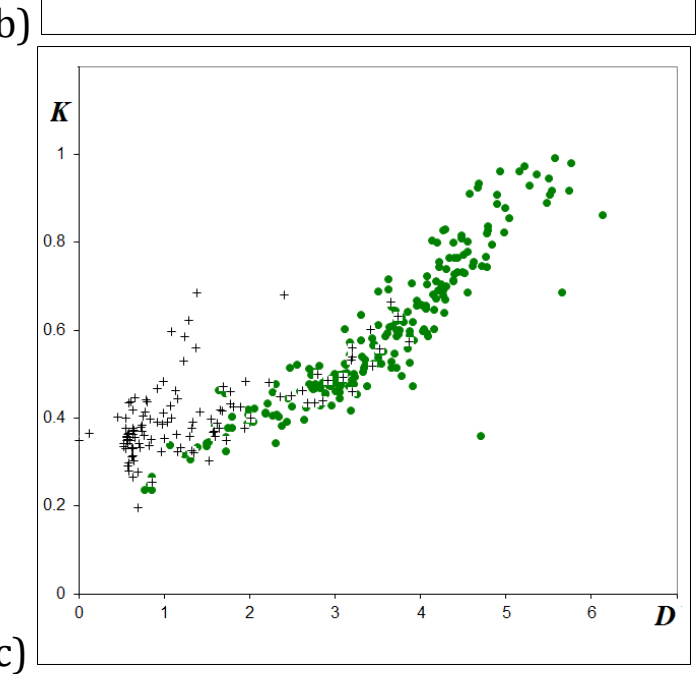

Fig. 4 2D presentation of the dependence of the coefficients $\mathrm{D}$ and $\mathrm{K}$ for the regions of (a) healthy enamel 1 and caries emanle 2; (b) healthy cement 1; (c) healthy dentin 1 and dentin with caries 2 .

Figure 4 presents the 2D dependence of the coefficients $\mathrm{D}$ and $\mathrm{K}$ in different regions of the tooth tissues. It is seen that the caries is characterised by reduction og the optical coefficients $\mathrm{D}$ and $\mathrm{K}$ due to the decreased content of $\left(\mathrm{PO}_{4}\right)^{3-}$ ions and amide $\mathrm{I}$ in the tooth tissue. From Fig. 4 (b, c) one observe the maximal relation of replacement of $\left(\mathrm{PO}_{4}\right)^{3-}$ with $\left(\mathrm{CO}_{3}\right)^{2-}$ (B-type substitution) with respect to the replacement of amide I 
with amide III. In the case of pathological change like caries, the shift towards the B-type substitution occurs. Thus the 2D dependences in Fig. 4 allow the determination not only of the type of the tooth tissue, but also the presence of pathologic changes.

For control we used the method of raster electron microscopy (REM). Figure 5 presents the microphotographs of the surface structure for healthy and caries tooth tissue samples.

a)

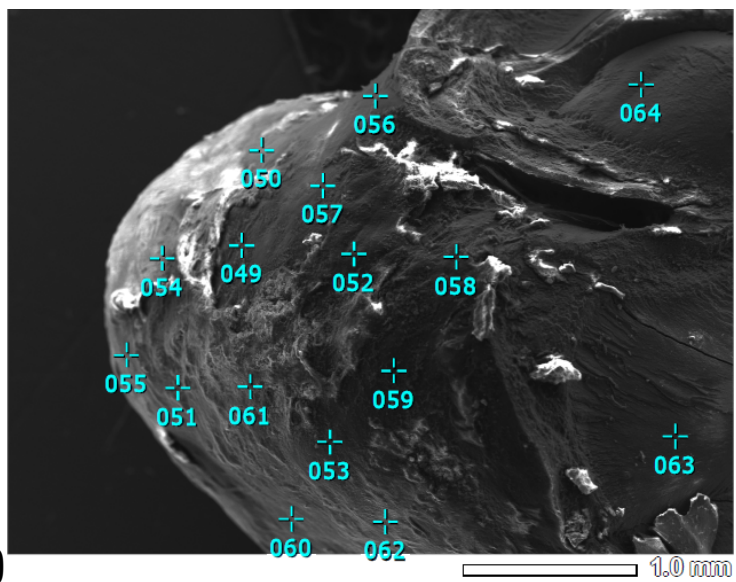

b)

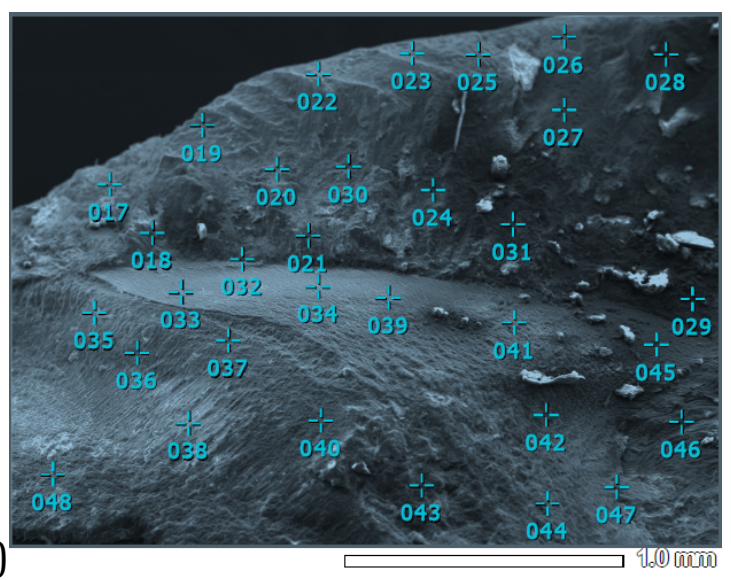

C)

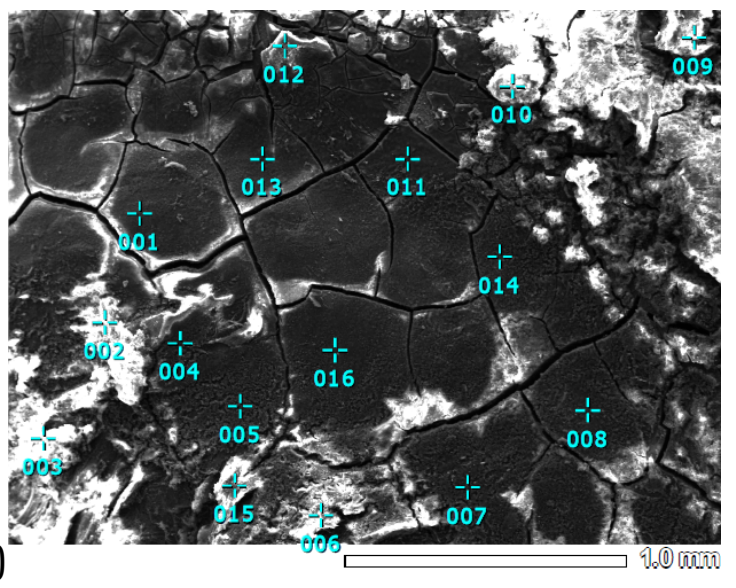

Fig. 5 Raster electron microscopy: a), b) - the healthy tooth tissue sections; c) - surface of the tooth with caries diagnosis.
According to the REM data on the element composition (Table 2) the caries samples are characterised by the reduced content of phosphorus and calcium and increased content of carbon and nitrogen, which confirms the obtained results and the reliability of the introduced coefficients.

Table 2 - REM data on the element composition.

\begin{tabular}{lcccc} 
& Enamel & Dentin & Cement & Dentin caries \\
\hline $\mathbf{C}$ & 29.49 & 33.07 & 50.72 & 59.63 \\
\hline $\mathbf{N}$ & 1.22 & 3.34 & 6.50 & 13.71 \\
\hline $\mathbf{O}$ & 37.42 & 37.15 & 18.22 & 17.38 \\
\hline $\mathbf{M g}$ & 0.17 & 0.42 & 0.92 & 0.04 \\
\hline $\mathbf{P}$ & 10.99 & 8.83 & 2.38 & 2.38 \\
\hline $\mathbf{C a}$ & 16.62 & 13.12 & 4.34 & 4.72 \\
\hline $\mathbf{I}$ & 2.42 & 1.94 & 0.73 & 0.75 \\
\hline $\mathbf{S e}$ & 0.01 & 0.05 & 0.02 & 0.04 \\
\hline $\mathbf{B r}$ & 0.52 & 0.73 & 15.62 & 0.05
\end{tabular}

\section{Conclusions}

We report the specific features of the Raman scattering spectrum for the healthy tooth tissues and those affected by caries. It is found that the caries is characterised by the change of the Raman spectrum at the lines with wavenumbers $956 \mathrm{~cm}^{-1}, 1069 \mathrm{~cm}^{-1}$, corresponding to phosphate, and $1241 \mathrm{~cm}^{-1}, 1660 \mathrm{~cm}^{-1}$, corresponding to amide III and amide I, respectively.

The 2D analysis of the introduced optical coefficients $\mathrm{D}$ and $\mathrm{K}$ is carried out that allowed the diagnostics of the beginning of the caries development in the hard tissues of the tooth. It is found that the caries is characterised by the reduction of $\left(\mathrm{PO}_{4}\right)^{3-}$ ions content and the change of amide composition in the tooth tissue.

According to the REM data on the element composition, the caries samples are characterised by the reduced content of phosphorus and calcium and increased content of carbon and nitrogen, which confirms the obtained results and the reliability of the introduced coefficients.

\section{Acknowledgments}

The work was supported by the Ministry of Education and Science of the Russian Federation. 